\title{
STRUCTURAL HEALTH MONITORING OF A HISTORIC CHURCH: THEORY AND PRACTICE OF DIAGNOSTIC APPROACHES USED TO CONTROL RISKS AND COSTS
}

\author{
DR. THOMAS MORRISON, PENG, ISCARSAH ${ }^{1 *}$ AND SONYA BURRILL, MSC \\ ${ }^{1}$ Heritage Standing Inc. (HSI) \\ PO Box 66, Stn A, Fredericton, NB, E3B 4Y2, Canada \\ e-mail: tmorrison@heritagestanding.ca, www.heritagestanding.ca (*corresponding author)
}

Keywords: Structural Health Monitoring, Masonry, Case Study, Damage Detection, Risk Mitigation

\begin{abstract}
Structural Health Monitoring is an exciting opportunity to use real time quantitative data of a structure's response in analysis and evaluation. However, this technology has yet to achieve common use in practice and remains linked to research of iconic buildings. This paper discusses the challenges and opportunities for use of SHM for widespread projects with damaged buildings and limited budgets. The SHM approach used was long term low frequency (static) data collection of both environmental inputs and structural responses. This data was used to develop relationships between loads and responses that could be effectively used to determine safety of the building and where in the structure deterioration continues.
\end{abstract}

\section{INTRODUCTION}

Structural health monitoring (SHM) provides an option for historic buildings with multiple limitations. For some historic buildings' owners must balance maintenance demands, constrained budgets, remote sites, and limited access to heritage professionals to avoid demolition. SHM can be used to objectively analyze safety and risk, allowing the professional to phase construction safely over longer periods of time, in alignment with the client's budget. Structural health monitoring provides data that is accessible through standard cellular service, reducing the need for frequent and costly remote site visits.

Stone Church, an unreinforced masonry structure built in 1826 in rural Eastern Canada, had significant structural deterioration issues due to a recent incompatible intervention. A full repair was not immediately possible, and closure for several months would likely have resulted in the closure of the parish and loss of the building. SHM was selected as the best option to meet these challenges by demonstrating building performance and safety. The system selected provided solutions for:

- monitoring damage from past incompatible repairs

- managing potential risk while building remains in use

- monitoring the success of phased construction 
- the distance of heritage professionals from the site

- a limited budget

\section{BACKGROUND}

Structural health monitoring is used extensively in industry for civic infrastructure, such as bridges and damns. ${ }^{[1]}$ Many of these approaches rely on data analytics and are often prohibitively expensive to apply to smaller and less well funded historic building. ${ }^{[2]}$ In the heritage community SHM systems have been applied to some iconic historic structures. ${ }^{[3]}$ The structures are typically culturally and financially well supported. They also benefit from long term study and monitoring by experienced heritage professionals. The use of vibrational analysis-based software for SHM alongside dynamic systems has become increasingly common, which allow the removal of environmental effects in evaluation to identify deficiencies occurring over time. ${ }^{[4]}$

Our approach applies SHM to control risk in lesser known, remote, and financially constrained sites where initial stability is unclear. By combining information from both structural and environmental inputs, this approach allows a more intuitive interpretation, and allows for understanding changes in structural stability due to climate-change induced weather pattern shifts.

\section{METHODOLOGY}

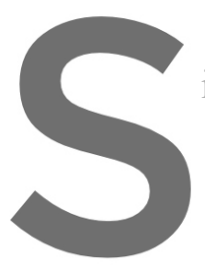

The conceptual structurate including Stone Church

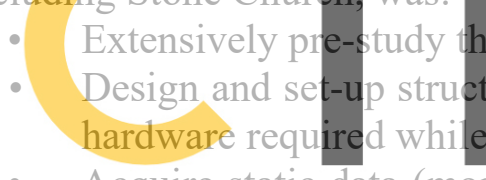

Acquire static dat
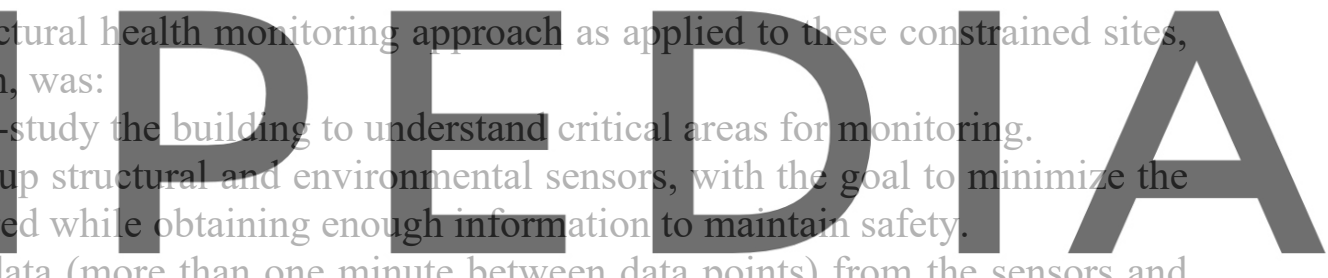

Register for free transmit to remote professionals and dynamic statistical analysis approaches. [?

- Combine numerical results with knowledge of the building to come to conclusions of safety and next steps.

The MIROVY software was benchmarked against two historic sites. Portugal's Oporto Cathedral and Monastery of Jerónimos had extensive ongoing structural monitoring and evaluation that provided base data sets for comparison.

\section{APPLICATION TO STONE CHURCH}

\subsection{Structural health monitoring system design}

The SHM system was designed in response to structural stability concerns in the Church. Past incompatible repairs, completed in 2007, were done on the front façade half of the building (including around the bell tower). An attached hall, which acted as a buttress for the western side of the building, was removed in 2015 .

The condition assessment noted the most urgent areas of concern:

- An archway, previously buttressed by the hall, was splaying. 
- Extensive deterioration of the masonry was found in the areas of the 2007 repairs. Deterioration included failure of the wall core, delamination of masonry wythes, and cracking indicative of the wall no longer functioning as a unified structural system.

- Significant new cracking was observed by the owners a few weeks prior to the first site visit.

The structural health monitoring system was designed to be as minimal as possible while monitoring the above structural vulnerabilities to allow for safe continued use. Environmental sensors were chosen to monitor conditions most likely to impact the chosen structural sensors. Figure 1 and figure 2 show the final placement of structural and environmental sensors for Stone Church.

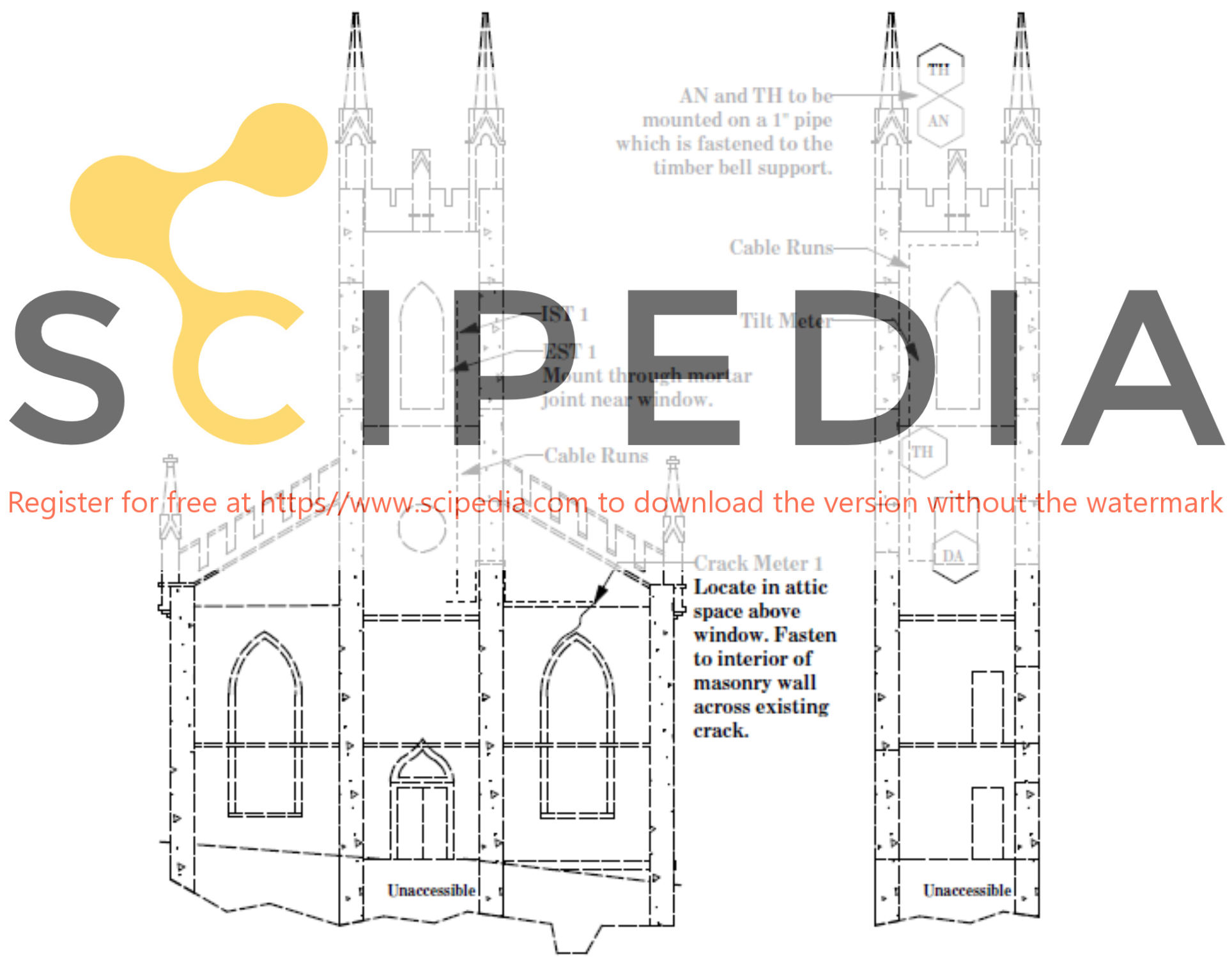

Figure 1. Sensor locations looking South and West. 


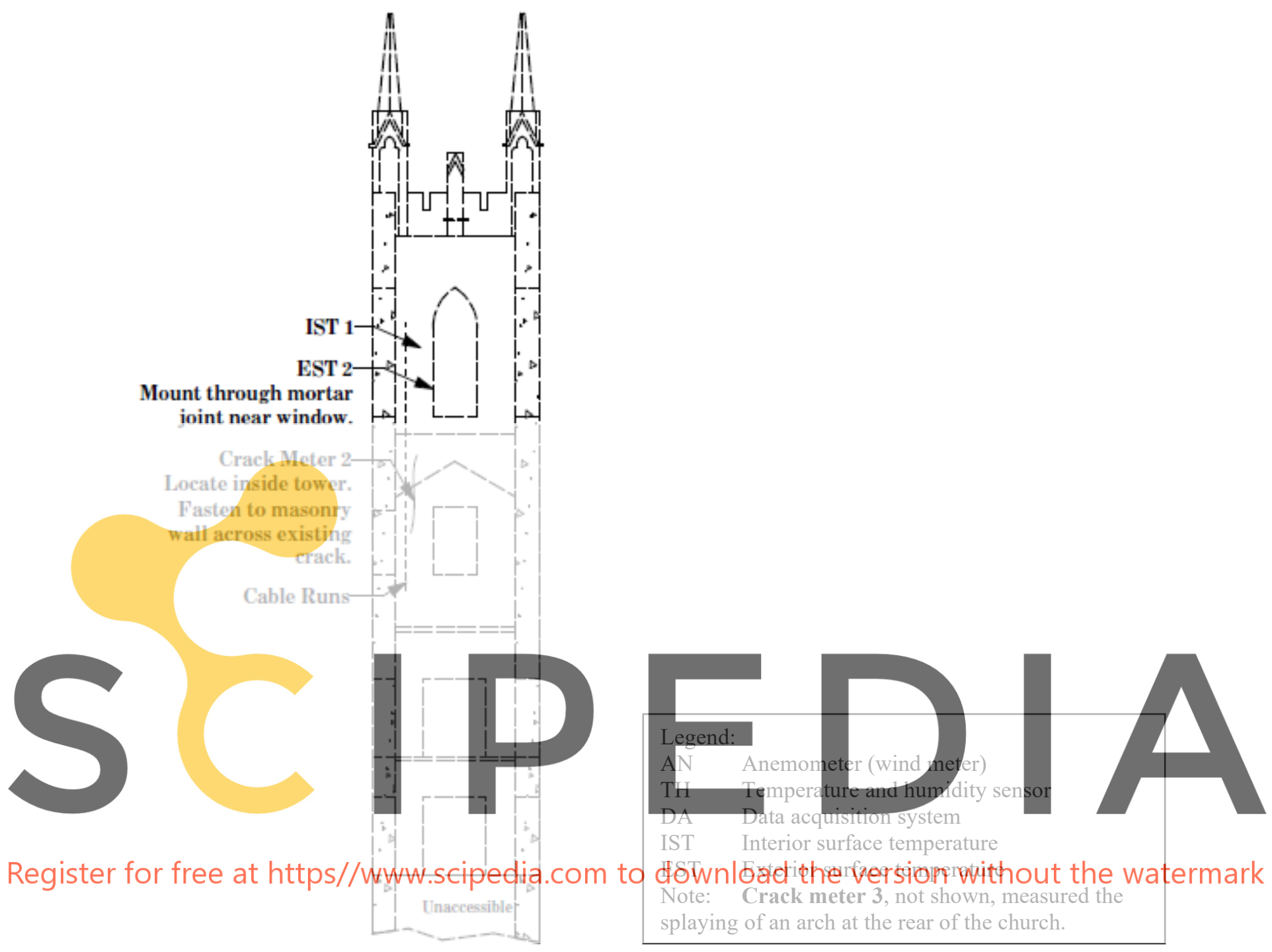

Figure 2. Sensor positions looking North.

\subsection{Short-term results}

Initial data was analyzed with direct results analysis, plotting sensor values over time. These plots confirmed the integrity of the data and became a baseline for future measurements..$^{[5,8]}$ They also allowed the professional to identify significant changes, such as the continual expansion of crack meter 3 (Figure 3). In other cases, the direct results analysis quickly informed users of problems; this plot of crack meter 2 showed that a sensor was knocked from its mount (Figure 4). 


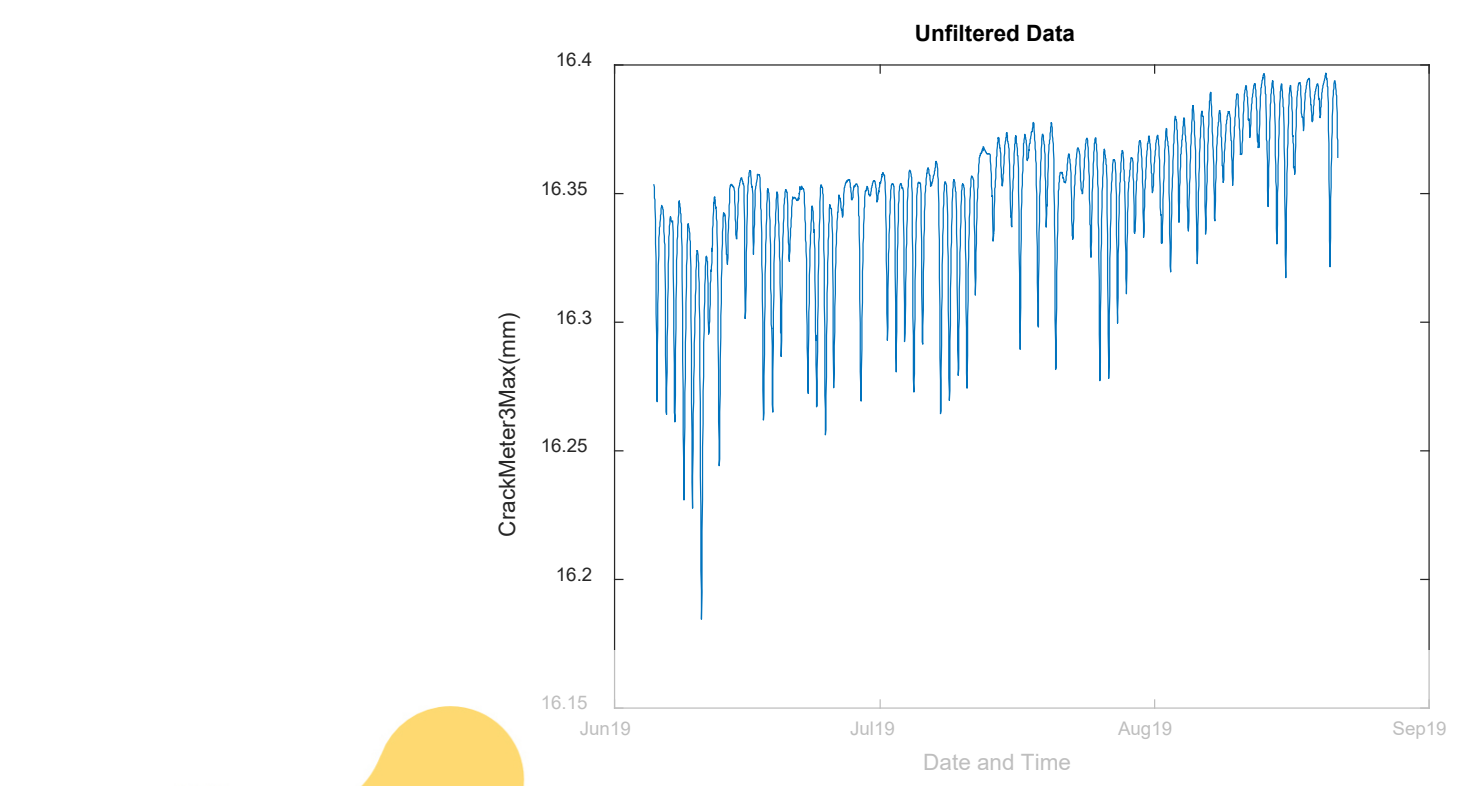

Figure 3. Continual expansion of Crack 3
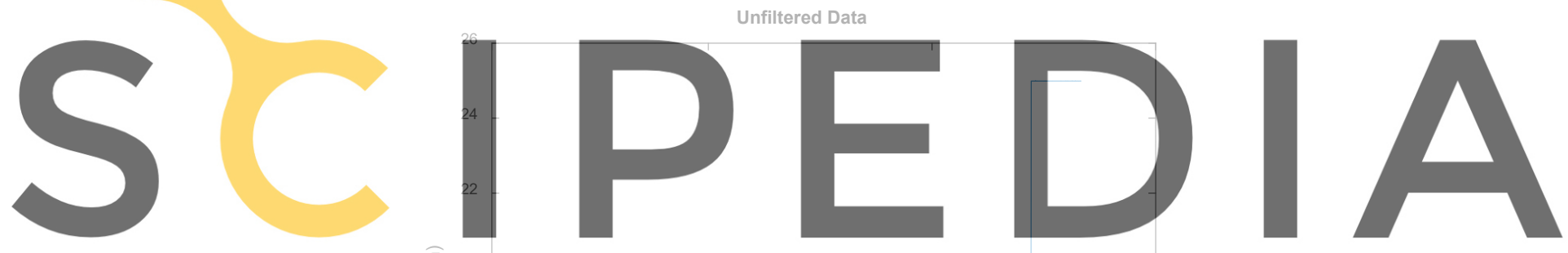

Register for free at https廉www.scipedia.com to download the version without the watermark

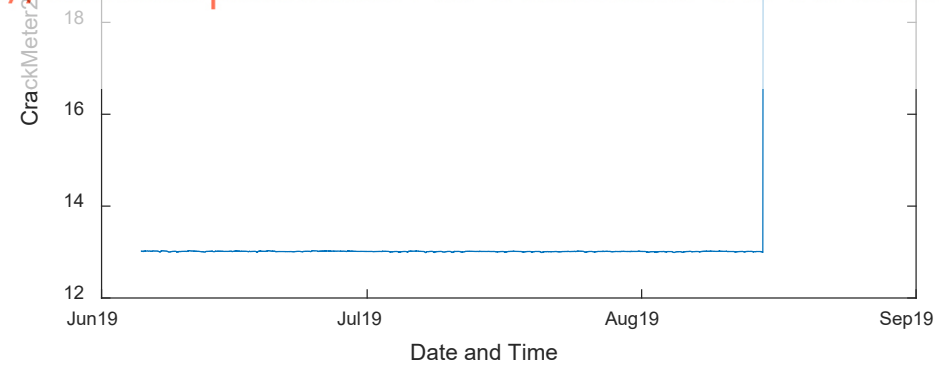

Figure 4. Crack Meter 2 knocked from its mount.

As the structural stability was a concern it was important to identify changes at as small a movement level as possible, focusing monitoring on trends and relationships so that problems could be addressed early.

The direct analysis plots also allowed the professional to quickly compare structural trends and environmental trends. Structural trends that showed no relation to environmental or use factors suggested gradual failure of a component. This did depend upon the correct environmental factors being included in the monitoring program. 
Early results provided simple statistical information: histograms were plotted to visualize the frequency of sensor measurements. Known statistical distributions should result, but when they did not, further investigation was undertaken (Figure 5). A coefficient of determination table was also developed for all signals, measuring the extent to which changes in a structural sensor were dependent on the changes in an environmental sensor. ${ }^{[9]}$

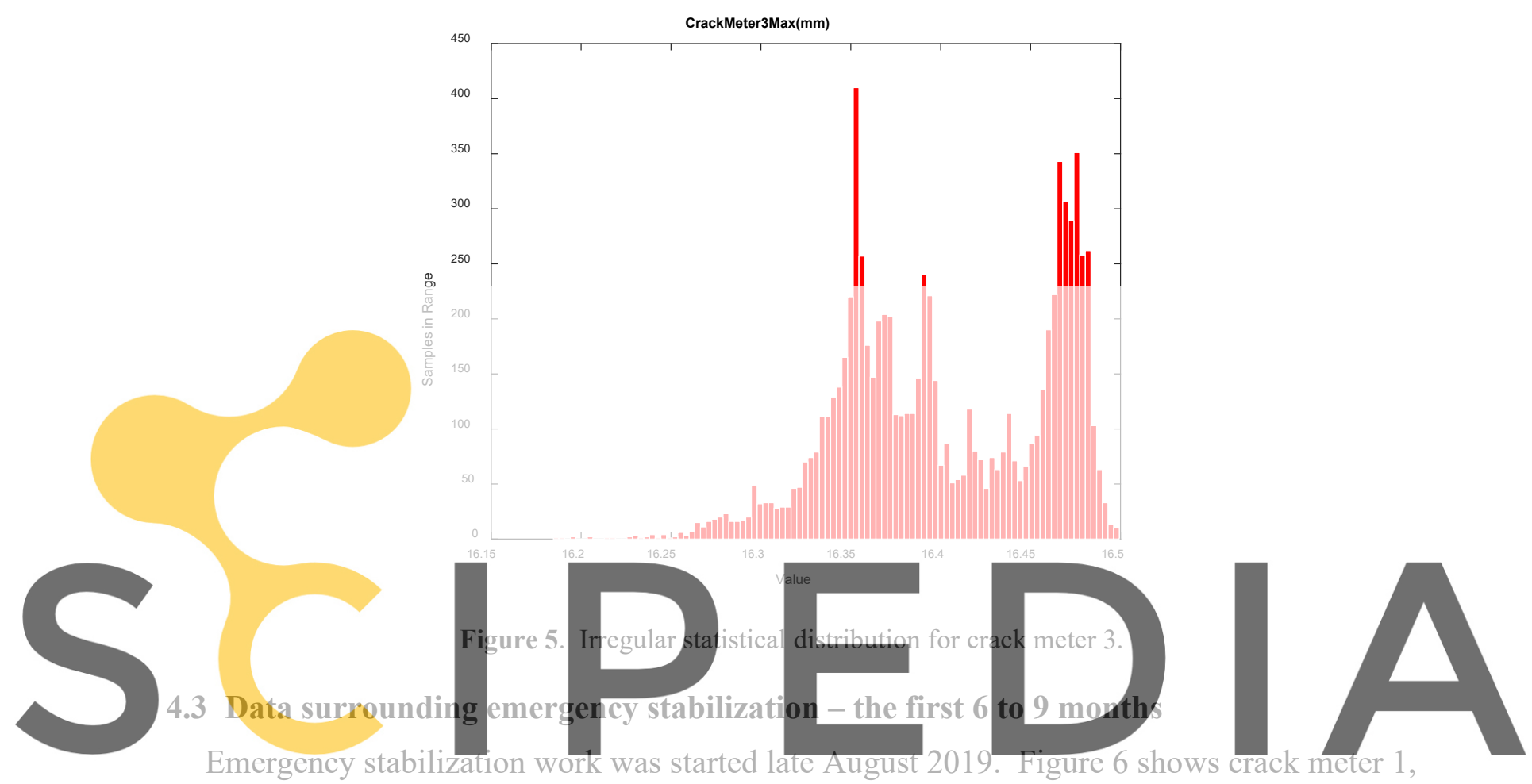

where following the intervention the amplitude of short-term movements noticeably decreased.

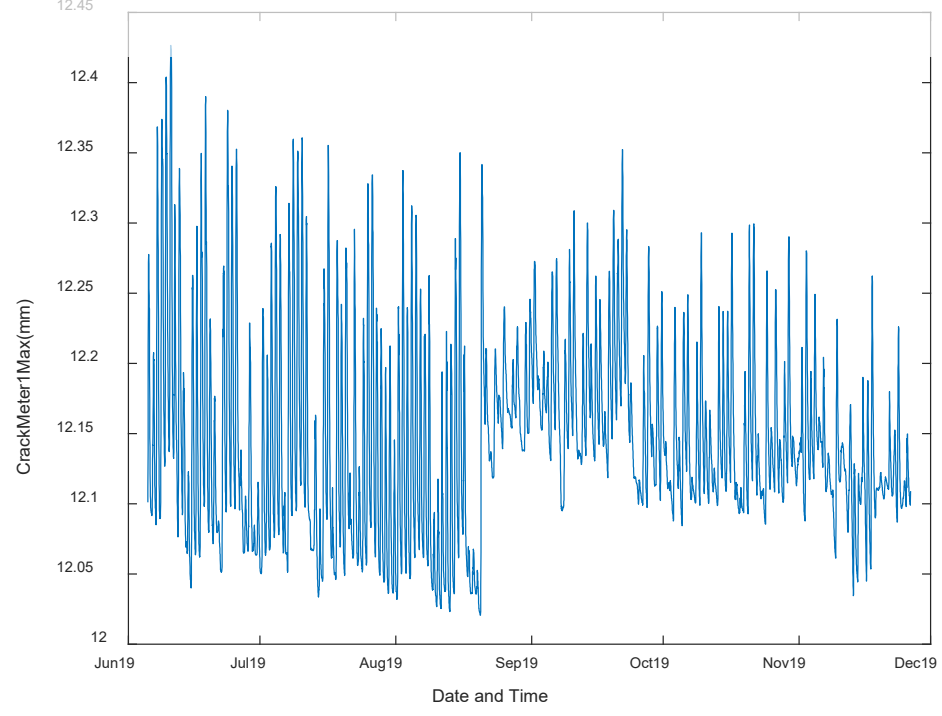

Figure 6. Before and after August 2019 construction work. 
The emergency stabilization work had a limited budget and focused on providing additional confinement for the masonry. Stainless steel rods and exterior mounted face plates were used in multiple locations, alongside mortar repairs in as many critical locations as possible. Changes in structural responses were seen immediately.

Along with direct results analysis and simple statistical evaluation, an algorithm for damage detection also provided evidence for improvement. Damage detection algorithms in the MIROVY program rely on two different statistical methods: standard deviation comparison and ARMA (auto-regressive moving average) dynamic regression. ${ }^{[9,10]}$ User selects the section of data from which the relationships are established, then projects this relationship for the entire signal. While these algorithms are more reliable for multi-year data sets, they were still beneficial for analyzing damage and improvement on shorter data sets. For example, after construction crack meter 3 showed more predictable behaviour (Figure 7).

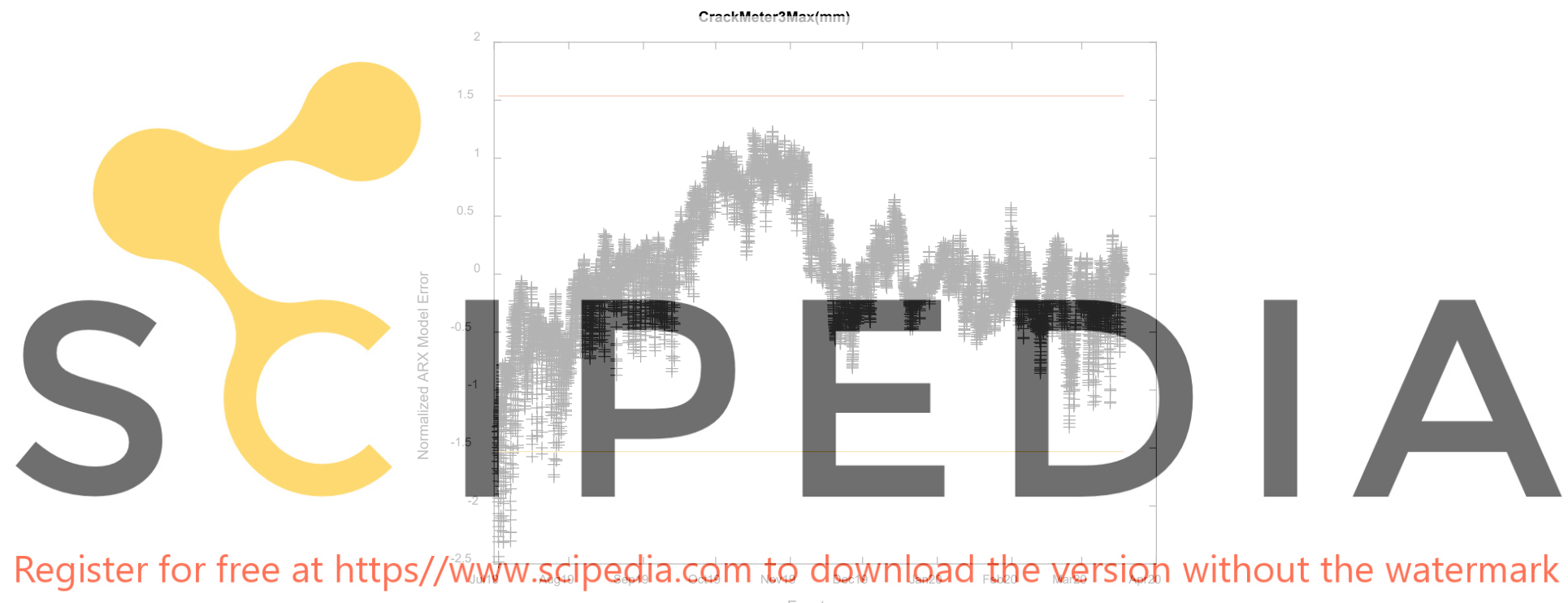

Figure 7. Reduced error in crack meter 3 after construction.

These initial results were beneficial in helping provide a means to establish temporary safety limits with the monitoring data as well as underlining that further intervention was necessary. With continued monitoring it was decided that the building could remain in use while the owners raised money in the coming years.

\subsection{Data from one to one and a half years}

With data covering more than one year of seasonal variations, baselines were better established and structural movements outside of the expected were easier to evaluate. Collecting environmental data allowed us to compare newly observed structural minimums and maximums with temperatures, opposing surface temperatures, humidity, or wind. For example, if newly observed tilt meter maximums corresponded to new maximums of wind speed, that would contribute to a possible explanation of the tilt meter's unexpected movement.

Longer term data allowed for the set-up of defined limits on sensors, which when exceeded 
would trigger an alarm that notified the owner and professional that unexpected behaviour was occurring. This would ensure that if unexpected changes occurred between pre-set evaluation times, those changes would be noticed and immediately addressed. The notification was to trigger a full data analysis to understand potential causes.

Data sets of longer than one year could benefit more from static regression analysis ${ }^{[11,12]}$ and dynamic regression analysis. For example, Figure 8 shows the multiple static regression analysis for comparing crack meter 3 with outside temperature, relative humidity, and surface temperature 2 difference. There is fair agreement between actual and modeled behaviour.
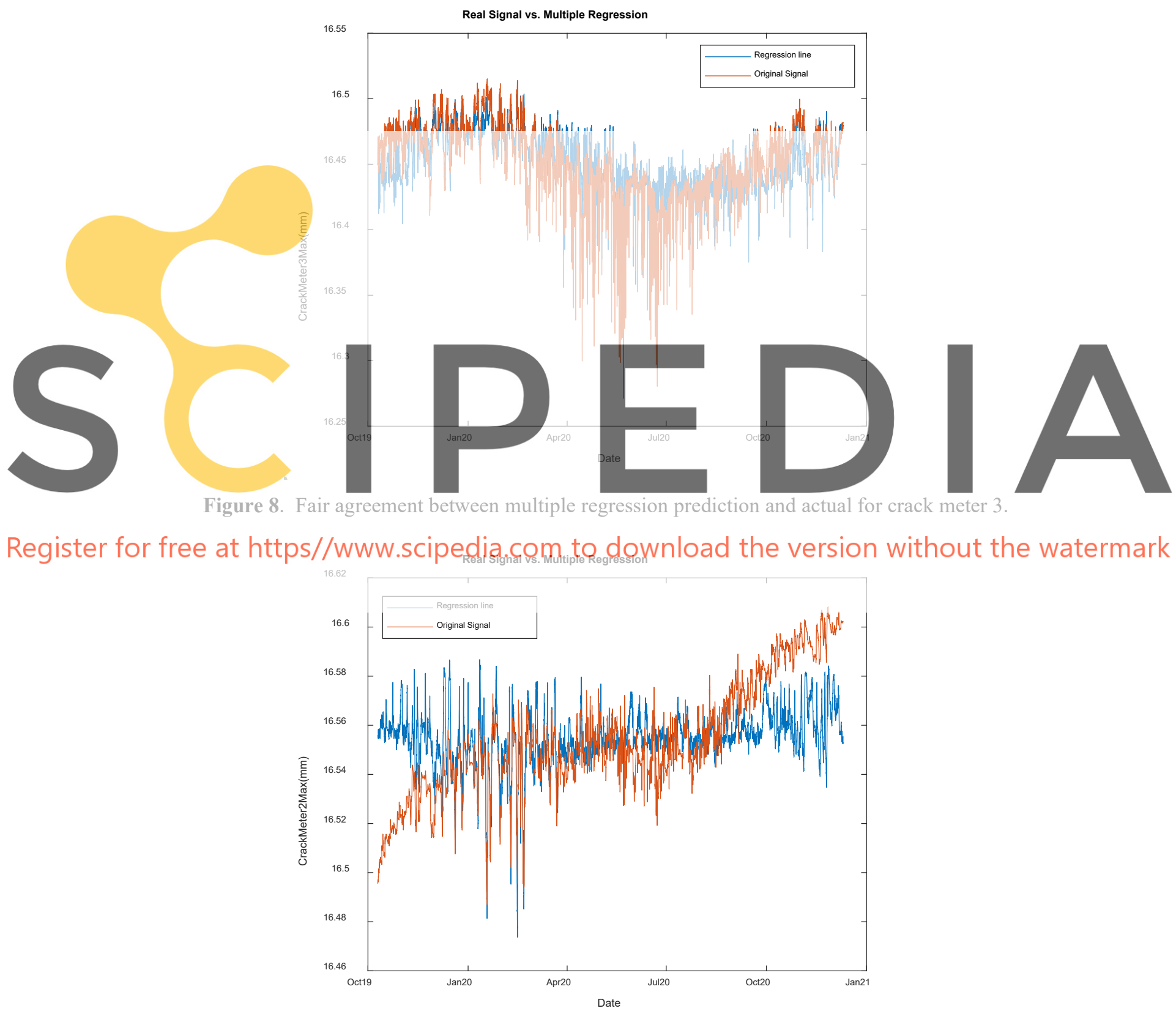

Figure 9. Poor agreement between multiple regression prediction and actual for crack meter 2. 
The same analysis for crack meter 2 (Figure 9) shows disagreement between actual and modeled behaviour, indicating that the continual expansion is not well modelled by changes in environmental effects and may require further investigation. Likewise, tilt meter B, NorthSouth movement, is not well modelled by environmental variables (Figure 10). Inclusion of max wind speed in the multiple regression modelling also showed that max wind speed was more relevant for tilt meter B than for any other structural sensor.

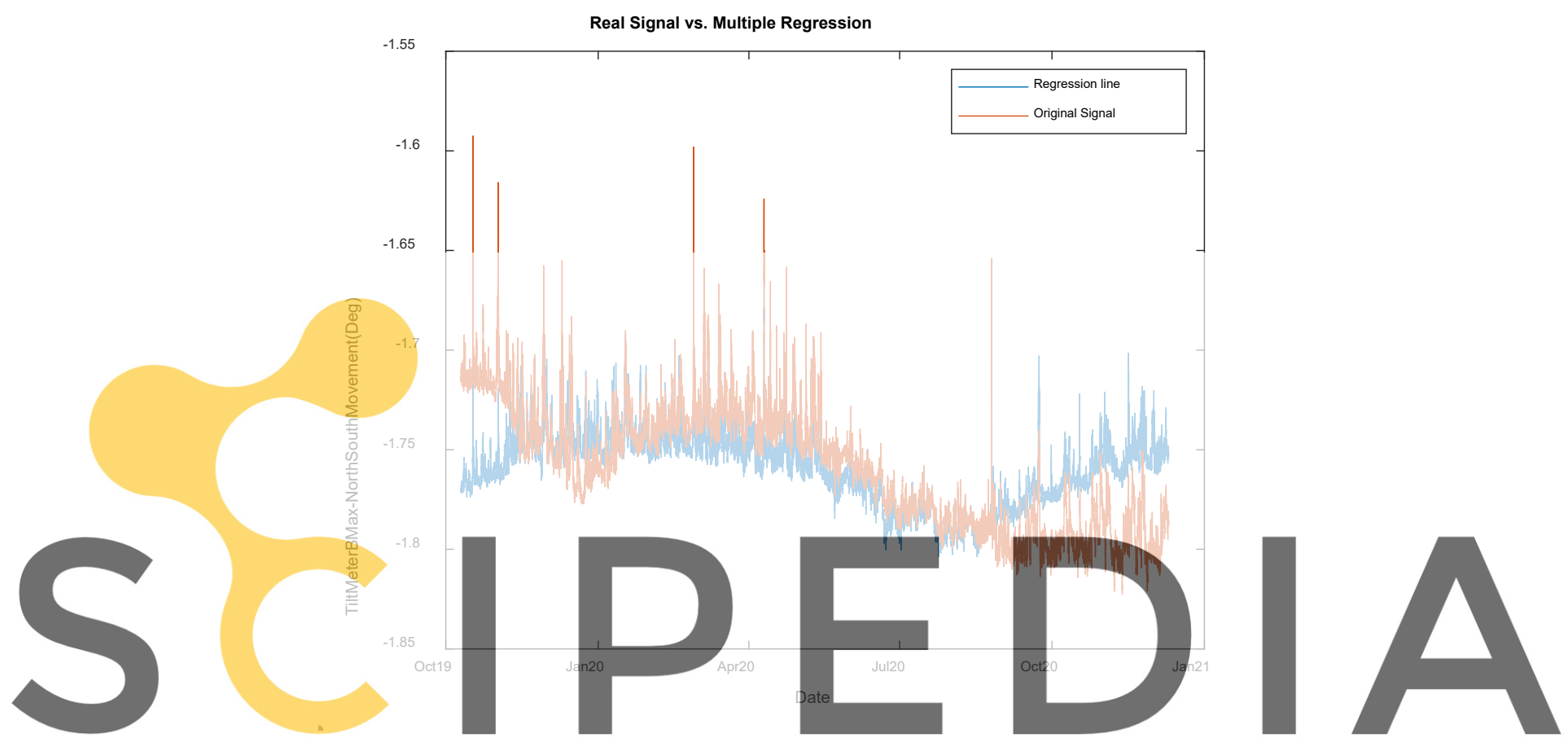

Figure 10. Multiple regression for tilt meter B

Register for free at https//www.scipedia.com to download the version without the watermark The damage detection algorithms, based on dynamic regression algorithms and produced from normalized values, considered results that included delayed factors, such a thermal inertia. ${ }^{[9,10]}$ The data set was divided into two sections. The first section was used to develop the model relationship between the structural sensor in question and relevant environmental variables. The second section provided structural predictions from the model, based on actual environmental measurements. The division between data used for the regression analysis and the predictions made was dependent upon building history and available data. For easier comparison one plot could be produced to show upper and lower bounds (set at a preferred standard deviation) and the difference between actual and predicted results. A second plot that showed the relationship as normalized model error provided easier visualization of trends in the predicted versus the actual value. If the structure were in good condition the error would remain within bounds with minor variation from start to end. If damage occurred after the control data, early in the signal, then the error would trend upwards or downwards late in the signal, extending beyond the bounds. Using dynamic regression-based damage detection analysis, figure 11 and figure 12 show a change in trends for tilt meter A, East-West movement. 


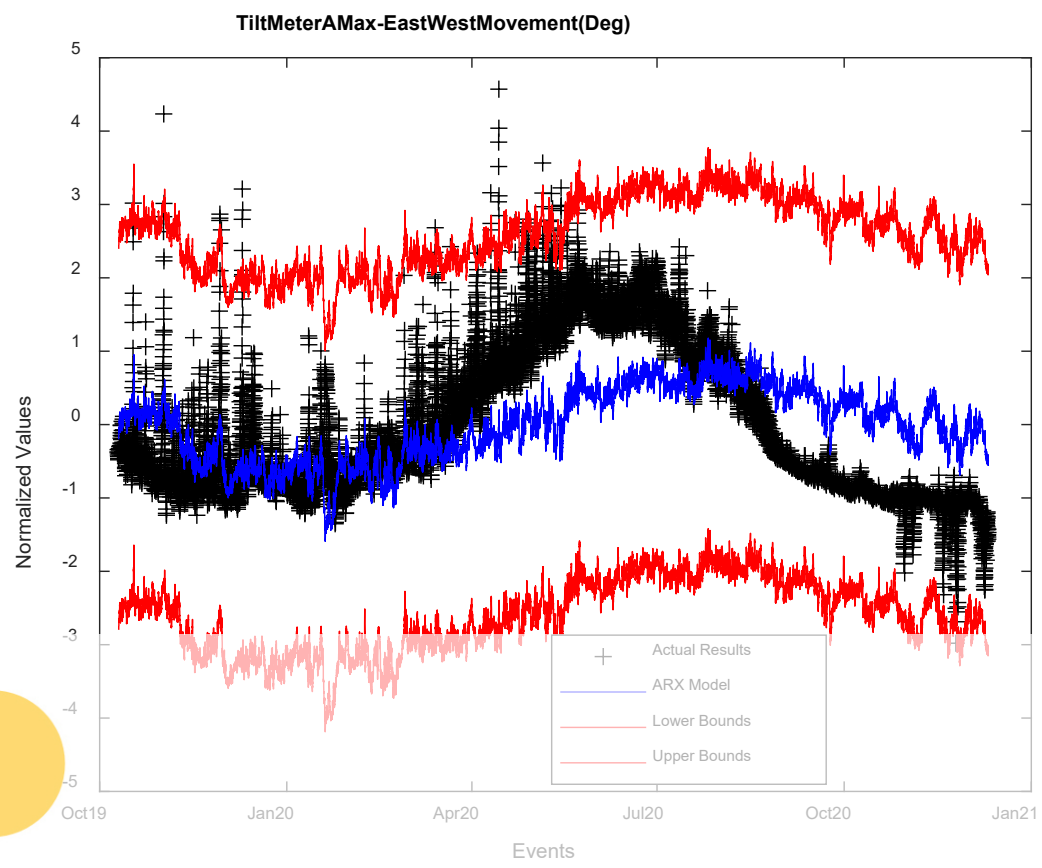

Figure 11. Tilt meter A dynamic regression damage detection.
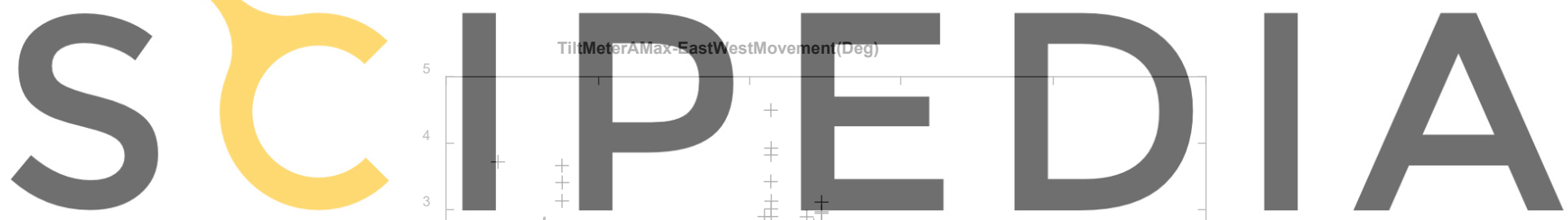

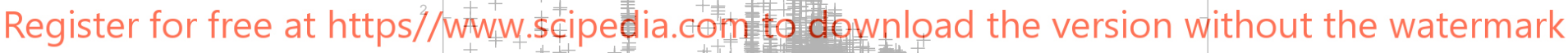

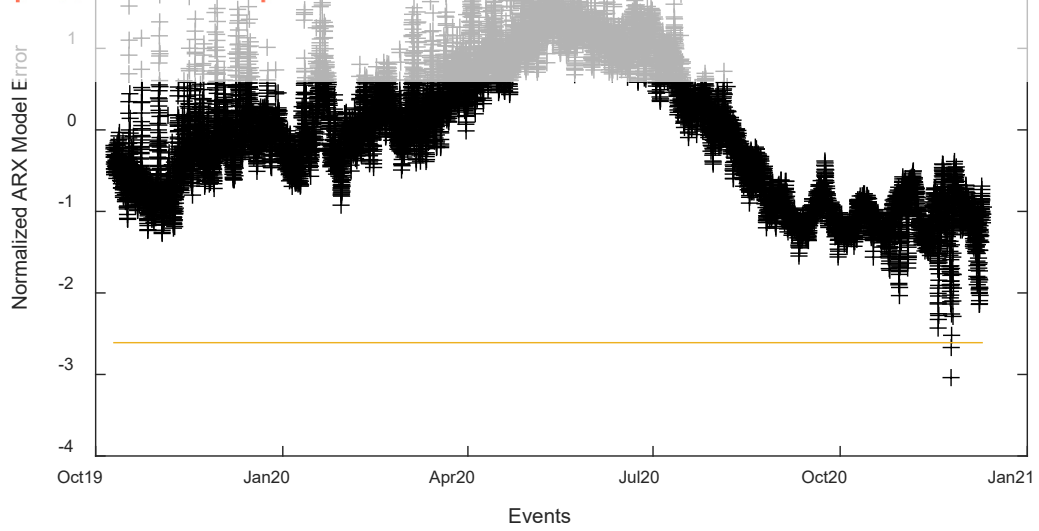

Figure 12. Tilt meter A dynamic regression model error

The most recent interpretation of data, which combined direct results analysis, simple statistical analysis, multiple static regression analysis, dynamic regression analysis and damage detection, found the following: 
- Interventions have provided benefit.

- Instabilities remain in the tower, and monitoring should continue.

- Crack meter 2 and tilt B, North-South movement, are still being closely monitored.

- The North wall and tower concerns remain, however the decision regarding which is the highest priority can be delayed for additional data.

- The difference in exterior and interior surface temperature on masonry response did not relate well to movements initially, but after two small sets of repairs the relationship has become important - as had been anticipated.

- $\quad$ Crack meter 3 has been stabilized.

This interpretation led to recommendations for the owner of continued monitoring, immediate reporting of new changes, a visual inspection in summer of 2021 and making plans to undertake additional building conservation projects (which could be linked to an upcoming major anniversary of the building).

\section{DISCUSSION AND CONCLUSION}

Our case studies confirmed that structural health monitoring could be successfully used to demonstrate building performance and safety for widespread application. Our base concept to use the relationship between the environmental causes and the structural responses to understand the building and meet client needs was successful. Additional advantages are provided with real time alarm for defined safety limits and regular professional monitoring of building performance without the necessity of site inspection.

Our SHM applications have also provided additional considerations. As we continue to collect data and analysis experience lessons include:

a) Only a small number of sensors are required, but what sensors and where must be carefully considered. Some redundancy is important as some sensors will likely be damaged during use.

b) Ensure the objectives and data analysis plans are prepared before implementation. Changes to data collection after starting monitoring create challenges for data processing.

c) Improved dynamic regression models would be valuable, particularly for wind data which may only have impact above specific thresholds.

d) Essential data will depend upon the site and the nature of the structural vulnerability being monitored. For the case study capturing wind gust data as well as interior and exterior surface temperatures was important to establishing expected performance.

e) A thorough understanding of the likely structural deficiencies and dynamics is necessary to determine and justify the monitoring required, and to interpret its meaning. This type of data would have limited value without this understanding.

f) Having a small number of likely theories to explain impacts to each structural sensor should guide identification of environmental data to be collected.

There remain many aspects of this SHM approach where further research would be beneficial. Finding ways to setup and run a system for low a budget situation requires considerable planning and knowledge. Determining how to make these processes accessible to a less specialized engineer would improve the ability for industry to take up the technology. Our ability to effectively use these tools for this type of project continues to rely on a small 
number of highly specialized engineers who have an intuitive understanding of structural dynamics and data. Our internal training has struggled, and we have lacked the resources to undertake some of the larger innovation necessary.

\section{REFERENCES}

[1] Pines, D. and Aktan, A.E. Status of structural health monitoring of long-span bridges in the United States. Prog. Struct. Engng. Mater. (2002), 4: 372-380.

[2] Gulgec N.S., Shahidi G.S., Matarazzo T.J., and Pakzad S.N. Current Challenges with BIGDATA Analytics in Structural Health Monitoring. In: Niezrecki C. (Eds.): Structural Health Monitoring \& Damage Detection, Volume 7. Conference Proceedings of the Society for Experimental Mechanics Series. Springer, Cham (2017).

[3] Oliveira, D., Ramos, L., Lourenco, P., and Roque, J. Structural Monitoring of the monastery of Jeronimos. Proceeding of the international conference on the $250^{\text {th }}$ Anniversary of the 1755 Lisbon Earthquake (2005), pp.466-473.

[4] Ramos, L.F. Damage Identification on Masonry Structures Based on Vibration Signatures. PhD Thesis: Universidad do Minho - Escola de Engenharia (2007).

[5] Morrison, T.E. Advanced Numerical Tool to Analyze Monitoring Data, Master's Thesis: University of Minho (2008).

[6] Peng, C., \& Zhang, B. A note on goodness-of-fit test of continuation ratio logistic regression models under case-control data. Journal of Statistical Planning and Inference (2008) pp. 2355-2365.

[7] Oliveira, D.V. Experimental and Numerical Analysis of Blocky Masonry Structures Under Cyclic Loading. Universidade do Minho (2003).

[8] Soong, T. T. Fundamentals of Probability and Statistics for Engineers. Chichester, West Sussex, England: Wiley-Interscience (2004).

[9] Smith, S.W. Digital Signal Processing: A practical Guide for Engineers and Scientists. London: Newnes - An Imprint of Elsevier Science (2003).

[10] Peeters, B. System Identification and Damage Detection in Civil Engineering. PhD Thesis: Catholic University of Leuven, Belgium (2000).

[11] Green, P., \& Silverman, B. Non-parametric Regression and Generalized Linear Models: A roughness penalty approach. London: Chapman \& Hall / CRC (2005)

[12] Hosmer, D. W., \& Lemeshow, S. Applied Logistic Regression: Second Edition. Chichester: Wiley-Interscience (2000). 